\section{Deep gas drilling divides the experts}

Could the answer to Sweden's lack of indigenous fuels lie 7.5 kilometres under a meteorite crater in central Sweden? When the drilling stopped at 6.3 kilometres for lack of money at the end of August some evidence had been obtained to support the controversial idea of Cornell University's Professor Thomas Gold that hydrocarbon gas deposits of non-biological origin are waiting to be found at such sites.

Drilling of the Gravberg borehole began in July 1986 under the leadership of Tord Lindbo of the state-owned power board, Vattenfall, which joined private investors in forming the company Dala Djupgas Provborrningar KB to back the project. Drilling at first went better than expected but then suffered various setbacks. While not discovering commercial quantities of

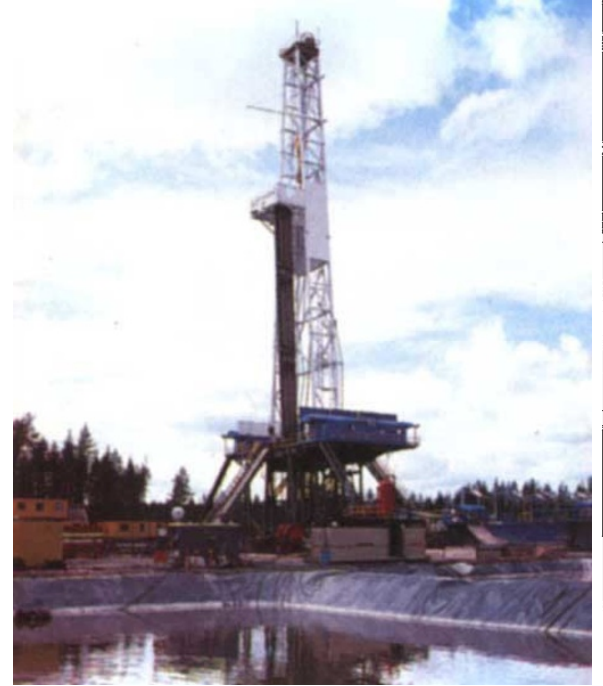

The deep gas drilling rig at Gravberg.

gases, a variety of hydrocarbons had been found in significant quantities. Critics maintain that these are artefacts of the drilling but Gold and Lindbo disagree, pointing in particular to the way in which the various gases track each other with depth. "There is no other circumstance that could have caused the correlations than that of their correlated entry into the wellbore from the formation", asserts Gold.

There is a particularly interesting seismic reflector at 7.2 kilometres, says Lindbo, who is keen to drill through it and optimistic that the private investors will pump in the extra SEK 20 million that would be needed to support the further three months of drilling. The scientific case for continuing is strong but the backers will need to be convinced that there remains a possibility of finding commercial quantities of gases. A considerable number of experts are being asked to assess the chances and, says Lindbo, commercial consultants are more optimistic than academics. A decision is expected by January.

\title{
In the cold without nuclear power?
}

SwEDEN was once sensible enough, from the British and Japanese perspective, to drive on the left-hand side of the road but the rarely used device of a public referendum led it to fall into line with its Nordic neighbours. The latest referendum, in the year following the accident at the US Three Mile Island nuclear reactor in 1979 , resulted in a parliamentary decision to shut down by the year 2010 the last of Sweden's 12 nuclear reactors, which produce 15 per cent of the country's total energy supply and half of its electricity.

Whereas the assumption in some circles was that this decision would later be overturned, the Chernobyl accident, from which Sweden received more radiation exposure than most countries, put paid to any immediate prospect of a change in public opinion at least. Therefore the country's energy policy and research is being increasingly driven by the prospect of survival without nuclear power, not least because 2010 is "almost tomorrow" for new energy investments, in the words of Leif Brandels, head of the planning office of the Statens Energiverk or National Energy Administration (NEA).

The NEA is the national coordinating energy authority in Sweden and is answerable to a ministerial department with a title of unusual significance - the Department of Environment and Energy. That title assumes particular relevance when it is appreciated that the energy planners have their hands tied regarding any expansion of Sweden's other main indigenous source of energy, hydroelectric power. On environmental grounds, parliament has declared that the hydroelectric potential of four northern rivers must stay untapped.

The problem is exacerbated by the country's almost complete lack of coal, natural gas or oil. For obvious reasons Sweden would be very reluctant to reverse its decreasing reliance on oil since the early 1970s achieved in part by the emergence of nuclear power

So what will substitute for nuclear power, which currently generates nearly 70 terrawatt-hours of energy? Most likely, says Brandels, at least $20 \mathrm{TWh}$ will have to come from imported natural gas, with Norway and the Soviet Union as the two most likely suppliers, unless the highly speculative deep gas drilling project (see left) proves successful. And efficiency measures can probably reduce demand by a further 20-30 TWh, mainly by cutting down the extent to which electricity is used for domestic heating.

With these needs in mind, and because Sweden suffers a cold climate, it is not surprising that the country is one of the highest spenders per capita on research and development in energy, although the $1987-90$ budget will be considerably less than the SEK 1,200 million spent by government on energy research and development in 1984-87. About half of this was related to energy supply and so was channelled through NEA in several areas.

Highest priority was given to combustion technology research with attention divided between the combustion processes themselves and the ways in which their toxic emissions can be minimized. Peat was the next priority since its use as a fuel has revived in the past decade. Research now concentrates on extraction and processing methods. Other NEA programmes are concerned with wood, wind and fuel consumption

\section{After Chernobyl}

AN impressive 300-page report with that title was completed at government's request within six months of the Chernobyl accident (26 April 1986). It investigates the consequences of Chernobyl for Swedish energy policy, nuclear safety, and both radiological and environmental protection, and it has two major conclusions.

The first is that there is no need to modify the technical risk assessments of the Swedish reactors or their design. A process, already begun, to upgrade protection measures against large-scale accidental release of radioactivity from the country's nine boilingwater and three pressurized-water reactors should continue, it concluded, but no extras measures are called for.

Second, it would not be possible to phase out nuclear power within ten years, rather than by 2010 , without a considerable increase in the cost of electricity. A ten-year phase out would rely largely on the generation of conventional coal-based power with sophisticated techniques to reduce sulphur and nitrogen oxide emissions, since extra hydropower is effectively ruled out, oil is too risky and time is too short to adapt to large-scale use of natural gas.

By sticking to 2010, there would be time to convert to gas but also the possibility of exploiting new technology that is in an advanced stage of development. In particular, gasification and pressure-fluidized bed combustion of coal are considered techniques of considerable promise, particularly in environmental terms. Wind power could also contribute; Sweden has two land-based plants in operation but it would need several thousand off-shore plants to replace current nuclear power production.

The government's response, not surprisingly, has been to hold to its original plans, estimating that the first of the nuclear plants could be closed in 1993-95. 